\title{
University computer-based teaching model of reflection and exploration
}

\author{
Ying WU \\ Shanghai University of Political Science and Law, Shanghai, China \\ wuying@shupl.edu.cn
}

\begin{abstract}
Used to reflect the concept of computer-based teaching, the teaching body to explore a conversion, that is possible to provide students with active development of space, students have continued the development of student ability, problem-solving teaching practical skills.

Index Terms - Computer teaching. teaching method. teaching relationship and teaching environment

\section{Introduction}

In recent years, the reform of teaching contents and curriculum have made significant achievements, but to improve teaching methods, teaching procedures and teaching methods, progress is slow. Obviously, we can no longer teaching the traditional subjects as well-organized and detail oriented knowledge, highlighting the computer's "discipline" rather played down the computer's special "tool" nature. Always in the classroom teacher-centered, teacher an instruction, a variety of teaching methods, students learn to imitate slavishly the state can no longer be allowed to continue.
\end{abstract}

\section{Reflect the Concept of Traditional Teaching}

We always used to put some ideas into the teaching of teaching the inevitable, for example:

A. Living Knowledge as "Dead" in the Implementation" of Teaching Dogma

In education, we often knowledge of the textbook as a conclusion, but the actual problem is always specific, at different times, different locations will be very different. For example, the operating system for smooth, recite the whole concept, but do not know that you are using Windows XP is the thing;

\section{B. Teaching as a Simple Copy and Knowledge Transfer}

That education is the textbook conclusion instill into the student's mind, teaching purpose is to conclusion tells the students, so that they understand, and memory down, so in the future when needed (most of the exam) can be applied to extract.

\section{Ignore the Experience of Cognitive Ability and Knowledge}

We often think that, in teaching before the students have to learn the basic theme in itself is ignorant, they have only some bits and pieces, one-sided knowledge base, which often impede the normal transfer of knowledge, the students themselves are unable or difficult to the formation of such knowledge, of course, will not solve the problem related to this. However, in today's computer has gone from "baby start", and students were not empty his head into the classroom, students in certain operational level of cognitive ability and experience (such as QQ, games, etc.) often become the teacher's teacher and materials, some of the steps the students easier, more effective methods of operation is often replaced by something. Therefore, in teaching the students to consider how existing knowledge and experience as a new growing point of knowledge for students of cognitive development to provide reliable protection.

For example, in the course, we always teach the basic concepts and some of the software used, but in many students actually used the software experience is worth our teachers learn. Some game features included in the operation of the software is far better than the general operation of the software much more complex. Should recognize that many students prefer the computer to understand and are beginning to start the game, how to start the game from the student's interest turned to learning is the teacher's challenge and an opportunity.

D. Too Much Emphasis on Understanding and Answers and Uniqueness of the Standard

Each student has their own unique experience, a wealth of psychological penetration in learning their own personality and style, often shown with a different understanding of the problem, different solutions to the problem. And teachers are often simply according to their own experiences and ideas, or textbooks for students to understand the logic to make right or wrong evaluation.

For example: In an Access database design process, the command button's text and the corresponding formatting should be in the "Properties" to complete, but many students are directly on the command button with a simple approach to solve similar WORD text format problem, straightforward, fast and effective. If teachers blindly adhere to the standards of operation rather than lead, in a comparative analysis of two methods to understand the pros and cons to living skills will become dead dogma of the situation.

In summary, if the emphasis textbook knowledge and absolute authority, the authority of teachers, so students can have a wealth of knowledge, but without their own ideas, the lack of analysis and criticism, lack of autonomy and independence; If the teaching only knowledge transfer and replication, then get the students thinking ability to explore 
training; If you ignore the experience and knowledge of cognitive ability, knowledge is divided into one small point, not the intellectual curiosity of students, but they spend original curiosity.

\section{In Teaching and Learning to Explore and Validate the New Model}

First, we must recognize from the theory of modern teaching should be the basic recognition of the problems: (1)clear teaching and learning is not the result of stimulation of education is to educate the student body within the environment and the psychological result of the interaction; (2) the main emphasis on cognitive learning dynamic role, students are active constructors of knowledge and meaning; (3) understand in developing effective teaching and learning environment has a huge role in learning; (4) advocate under the guidance of teachers, student-centered learning.

On this basis, the teaching should not only impart knowledge and training tools, it should be to develop means of cognition. Should encourage students to actively participate in teaching activities. Since each student's creativity is valued, the teacher's authority will no longer be based on the students on the basis of passive acceptance, but on teachers with students actively involved in the ability to promote the full development of the above.

So how in teaching practice to explore and validate some of the new teaching model?

\section{A. Identify New Teaching, Learning Goal}

Imparting knowledge and acceptance is a process, the ultimate use of knowledge to solve problems is to teach, the purpose of learning and change so that "results speak for themselves, so that tests to prove" the point of view, usually results in the curriculum to increase the proportion $(30 \%$ to $50 \%$ ), the operational capability, hands-on problem-solving skills in computer-based teaching in the re-positioning. In the beginning of a book still in place today, exam-based teaching and learning environment, the importance of the actual normal operating practice, reduce Juanmian test in the ultimate measure of the proportion of students is a stopgap measure.

\section{B. Develop New Teaching, Learning Relationship}

So that teachers from the "educator" role to "guide" role up, for example, in the WORD of teaching, with the planned 1/4 time to teaching the content of textbooks as the "leading" to explain, but the teaching time 3/4 left to study in the subject students, based on his WORD by their experience to develop practical use, not mentioned in the general teaching function, and provide presentations for each developer, the opportunity to explain and to promote the development of students for each function to be "judgmental", the students based solely on their own knowledge framework to come into play to their strengths to learn, understand and master the curriculum is a high level and depth.

At the same time in the curriculum and the assignment can explain the reference to the concept and practice of collaborative learning. Collaborative learning is a learning task for the same number of learners to exchange information and cooperate in order to achieve a deep understanding of the knowledge and mastery. Collaborative learning to improve learning, the formation of learning critical thinking and creative thinking, and communication between the individual students ability to have a significant positive effect. Teachers in lectures, on the one hand through the small but efficient about to grasp the whole process of teaching the content and direction, the other as far as possible to retain some similarity with the old knowledge of the law of new knowledge, to guide the students themselves to find it, where possible, conditions, organize the students to discuss and exchange, and for students there are more problems and difficulties, professors and students in the analysis and discussion so that students gain confidence in their ability to sense the same time, knowledge and understanding will be further deepened.

\section{Implementation of the New Teaching, Learning Process}

In the computer-based teaching is almost invariably the first theory to explain, after the practical operation. But theory is often complex, abstract and sometimes difficult to understand, such as the three models in the database and two mappings between them, the first database design paradigm, the second paradigm ... and practice is relatively more seems simple and easy to understand. We have often advocated the teaching of the first Simply put the solution, so that students can have a hazy understanding of the can, and then depending on the operating depth, the theory began to be involved to explain the relevance of the final sum to a user-friendly on the theory and operation of fusion, the in-depth analysis to explain, so that students gradually through the operation to deepen the theory of reasoning, analysis to consciously understand and grasp.

\section{Implementation of the New Teaching, Learning Methods}

Focus on the students to analyze and problem-solving abilities and innovative cultivation. For example, in database technology, the process of teaching students special attention to the specific steps, and the database design process, principles and methods of lack of interest. By "different education", select a group of students to the knowledge of design principles and methods based on more complete and reasonable to complete the database model, as an example, so that all students feel the "fish" and "fish" value. Specific methods are:

1) Induced Interest-based Learning: the teaching process through the appropriate change and stimulate student interest and attract the attention of students, will introduce students to a certain problem situation, to enable students to go in the original basis of cognitive structure and conform to current assimilation of new knowledge learned. For example VB program does not have a long course designed to introduce the system, there is no function to explain the menu, not the language syntax, but to give students a good game demo with VB classes, music classes, animation classes small program, so that students VB personally feel the operability and visibility, VB students interest and enthusiasm of the students 
spontaneously, thinking become active and start thinking about how to use VB to implement these features of his own imagination interesting events, and are eager to immediately to learn to master these skills.

2) Emphasis on the Learning Environment Inspired by Thinking: should be good to create a situation conducive to the learning content, so that students can focus on issues initiated learning. For example, he spoke of the VB in the FOR loop, you can use based on previously learned IF-THEN and GOTO statements to explain. Two different statements to solve the same problem, both compared the difference between the two, but also on the basis of the existing knowledge on the FOR loop to deepen awareness and understanding in order to achieve a combination of, the purpose of consolidating and improving. And this process, the organization of teachers, guidance, help and promote the role, so that students initiative and creativity into full play, improve teaching efficiency.

3) to Foster Innovation in Imitation: imitation to a certain extent, reduce the difficulty of the knowledge, confidence and learning to keep students interested. Teachers, according to the teaching objectives and students' cognitive characteristics, the design of appropriate, replicable examples to guide students to master knowledge. For example, teachers are given first, the program has been programmed by demonstration and explanation to give students a basic understanding of, and then let the students imitate the example groups of three, while on the machine operation, while analysis and discussion with a statement from the imitation of the experience programming method. When students solve these problems by imitating the teacher to guide students to realize that in imitation of the perceptual, and then a bit of variety to the innovation of a new similar process. In order to solve these problems, students will take the initiative to read a lot of extra-curricular books and related magazines and newspapers, and another heated discussion. Final adoption of the summary, to find out the solution to the problem. Thus, although the example is a study in imitation, but learned to solve similar problems, students can learn by analogy on this basis and solve related problems in order to develop the student's creativity, analytical thinking, problem-solving abilities.

4) That is Used to Create the Effect of School: to apply their knowledge to any one discipline is the goal, as the computer's operability and application characteristics, so that computer science will soon learn that with respect unique. As a tool to study computer without too much emphasis on systematic application of each of its modules can be relatively independent, you can learn a little bit, like learn Chinese character input, can be entered into the computer, learn a text editor, you can layout, and so on. Soon learn that the process used the student's own ability to be sure, to enhance students' self-confidence, so that students feel there is always new challenges, new excitement, then it will maintain and promote the enthusiasm of students, they can further stimulate interest in students to continue learning the computer, forming a virtuous circle.
In the classroom teaching and implementing the schoolto-use method of teaching content in the back need to add some small tasks to solve practical problems, to ensure that these tasks with the previously learned knowledge are closely linked. After a learning phase, requires a comprehensive layout of the big tasks embodied previously learned knowledge. For example, in multimedia teaching to allow students to make their first Flash work, make the Windows desktop "wallpaper", when the students see the "desktop" is put on his own work, there is naturally excited. So soon learn that with the objects of learning tasks in the leaving enough space for students, allowing them to imagine, to think, to design, to be innovative.

5) the Implementation of an Individualized Education Strategy: in the computer classroom, student interest in learning to mobilize and protect the enthusiasm of the students, but also individualized. As the saying goes: ten fingers sticking out is not generally long, not to mention we are faced with hundreds of students and the difference between the very obvious. As a good teacher can not allow a walk in front of students marking time, doing nothing; not allow students to catch up the back, loss of confidence, give up. Operability of the computer itself but also for our individualized instruction provided favorable conditions, is designed for students and improve basic work-type task, each student must complete a basic task, improve the type of task is the completion of the basic type of students choose after the operation. Let go by in front of students to the challenges of new technologies, and let the students go in the back can also temporarily in a relaxed learning environment for students to catch up with the front.

\section{4. to Create the Implementation, Promotion of New Teaching, Learning Mode environment}

Bruner that "the acquisition of knowledge is an active process, learners should not be passive recipients of information, but should be active participants in knowledge acquisition."

So to create conducive to innovation in teaching, learning environment, when the students thinking beyond the activities and findings and expectations of teachers designed the track, the teacher should not force the students into their own mode of thinking of thinking among the teachers should be good to encourage students to boldly challenge, students of teachers, teaching critical skills to enable students to gradually have a sense of innovation. For example, in the classroom teaching process, when the time to explain a procedure, often put forward different views of students, regardless of their view is correct or not, teachers should not simply negative, but should guide the students to examine their views, to guide its draw the right conclusions.

By teachers to encourage, guide, protect the enthusiasm of the students to think independently, while also enable students to establish self-confidence to innovate, and to innovative thinking throughout the innovation environment in the active state. Our approach is divided into three levels: 


\section{A. Inspired Style Guide}

Is to use a variety of effective ways to inspire and guide students, to stimulate student interest. If the theory can be used to prompt thinking, divergent thinking, extensive discussion, encouraging speculation that other ways to inspire and guide students. For example, when talking about Moore's Law, organized students to discuss the "Pentium 4" is replaced by the time talking about the operating system, organizing students for Windows 2000 and XP that both sides of the debate, in the web design process started, "how you are Zhang chao-yang, Sohu's home need to adapt? "discussion ... ... to stimulate students' thinking and creativity, divergent thinking of students.

\section{B. to Promote Problem}

In teaching, attention to teaching materials in the mining potential of the educational factors, problem-forward mode to full play the main role in the creation of a relaxed, equality, and innovative spirit of the teaching situation, to change the teacher "mouthpiece" or sing "one-man show." the old method, but also students to self-learning and study time and space. With learning problems to every level to promote student thinking, problem-solving abilities. Each task is divided into two levels of teaching, easy to understand and difficult, and the classroom only to explain the former, the latter the students, in practice, the operation to enlightenment, and ultimately by some students independently, and then by the students in the to all students about the classroom, to promote all students the ability to solve problems independently.

Teaching in the program design, in general, the implementation of the program cycle, the use of loop branch statement than to use a program written in a simple and reasonable, but there is no exception? What circumstances a branch statement with a more appropriate? Inspire students to summarize a variety of situations, to more deeply understand the loop structure. Thus, by heuristic teaching so that students active thinking, encouraging students to think from different angles, using different methods to solve problems, promote the development of creative thinking of students.

\section{Resource Type Deepen}

Is based on the basic problem-solving, requiring students to use various types of network resources for intensive study. Use a certain amount of network communication skills and information retrieval capabilities for more comprehensive information to supplement and deepen understanding of course content.Teaching and research in building an innovative educational environment based on the measures to be taken to implement and test, such as between the various teaching units of the contest theme of the organization must, in innovative education for teachers to give tests, but also the innovative achievements of students incentives, and exchange of outstanding works on the network. This not only provides students with autonomy, individual initiative and performance opportunities, but also in the formation of strong campus advocating innovation, respect for the creative talents of the atmosphere.

\section{Conclusion}

In building a harmonious society, environment, our computer-based education, there are many things to do, our vision:

\section{A. Experimental Base Construction}

Building local area network, allowing students to design, set up a small network system has been operating in practice, and through the actual network to complete some course content, improve their ability and actual ability to solve network problems, another example, the use of virtual reality simulation or fictitious certain situations, for students to observe, manipulate, construct one of the objects, so they get to experience or be discovered. For example, some software system designed so that students can use it to provide a variety of analog circuit structural components and digital circuitry, and can dynamically test the circuit performance.

\section{B. Implementation of the Teaching Simulation}

The use of computer modeling and simulation technology to show the structure and dynamics of some systems, to provide students with an alternative environment for their experience and observation. Computer simulations allow students to input data by changing the size of changes in observing systems, such as the operating system's virtual memory, environment variables, etc. Teaching simulation software to provide students with a non-hazardous, nonexpensive way to interact with the real world. Students operating model elements, changing the model of different variables to get different results.Teaching in the operating system, many of the teaching content is the need to operate in practice, but the school room of equipment is not easily modified to enable students to operate, if they have teaching simulation software can greatly improve the teaching environment.

\section{References}

[1] Liu Caihong, Qi Ruihua. Liberal arts college levels of teaching basic computer courses computer education, 2009 (9): 68-69

[2] Wang Jun Ling, research-based education model of. Higher Education of Sciences, 2009 (2): 90-92

[3] Chen Wei. Overview of constructivist learning theory. Academic exchange, 2009 (3): 175-177

[4] International Society of Technology in Education (2000). National Educational Tchnology Standards for Student.Engene, OR: Author 